\title{
A quantitative assessment of the views of mental health professionals on exercise for people with mental illness: perspectives from a low-resource setting
}

\author{
Davy Vancampfort ${ }^{1,2}$, Robert Stanton ${ }^{3}$, Michel Probst ${ }^{1}$, Marc De Hert ${ }^{1}$, Ruud van Winkel ${ }^{4}$, \\ Inez Myin-Germeys ${ }^{4}$, Eugene Kinyanda ${ }^{5,6,7}$, James Mugisha,
}

1. KU Leuven Department of Rehabilitation Sciences, Leuven, Belgium.

2. KU Leuven, University Psychiatric Center KU Leuven, Leuven-Kortenberg, Belgium.

3. Central Queensland University, School of Health. Medical and Applied Sciences, North Rockhampton, Australia.

4. KU Leuven, Centre for Contexual Psychiatry, Leuven, Belgium.

5. MRC/UVRI, Uganda Research Unit on AIDS, Entebbe, Uganda.

6. Department of Psychiatry, Makerere College of Health Sciences, Kampala, Uganda.

7. Senior Wellcome Trust Fellowship, London.

8. Butabika National Referral Mental Hospital, Kampala, Uganda.

9. Kyambogo University, Kampala, Uganda.

\begin{abstract}
Background: Exercise is nowadays considered as an evidence-based treatment modality in people with mental illness. Nurses and occupational therapists working in low-resourced mental health settings are well-placed to provide exercise advice for people with mental illness..

Objectives: We examined the current exercise prescription practices employed by Ugandan health care professionals when working with people with mental illness, and identified perceived barriers to exercise prescription and exercise participation for people with mental illness.

Methods: In this study, 31 Ugandan health care professionals 20 men; $31.2 \pm 7.1$ years completed the Exercise in Mental Illness Questionnaire- Health Professionals Version EMIQ-HP.

Results: The vast majority of the respondents $29 / 31,94 \%$ reported they prescribed exercise at least "occasionally" to people with mental illness. Exercise-prescription parameters used were consistent with those recommended for people with mental illness. Regarding barriers to exercise participation, coping with side effects of psychotropic medication at the individual level and reducing stigma at community level should be prioritized.

Conclusion: A health care reform to enable collaboration with exercise professionals, such as exercise physiologists or physiotherapists, might increase exercise uptake for people with mental illness, thereby improving health outcomes for this vulnerable population.
\end{abstract}

Keywords: Exercise; physical activity.

DOI: https://dx.doi.org/10.4314/ahs.v19i2.42

Cite as: Vancampfort D, Stanton R, Probst M, De Hert M, van Winkel R, Myin-Germeys I, Kinyanda E, Mugisha J. A quantitative assessment of the views of mental health professionals on exercise as treatment for people with mental illness: perspectives from a low-resource setting. Afri Health Sci.2019;19(2): 2172-2182. bttps:// dx.doi.org/10.4314/abs.v19i2.42

\section{Corresponding author:}

Davy Vancampfort,

Tervuursevest 101

3001 Leuven,

Belgium

Tel.: +32 27580511

Fax: +32 27599879 .

E-mail address: davy.vancampfort@kuleuven.be

\section{Introduction}

Mental illness is the leading cause of years lived with disability YLD in sub-Saharan Africa SSA, accounting for about one fifth of all disability-associated burden YLD ${ }^{1}$. It is estimated that the burden will more than double by 2050 Institute for Health Metrics and Evaluation, 2013. The consequences of the rising and devastating burden of mental illness is not only having an impact on the individual but also on the family and community as a whole. 
The quality of life of those affected is severely reduced and economic costs are significant ${ }^{2}$. Moreover, physical co-morbidities $^{3,4}$, chronic pain $^{5,6}$ and HIV/AIDS ${ }^{7,8}$ are more common in people with mental illness and add to the disability and burden. Despite this tremendous burden,most SSA countries invest less than $1 \%$ of the total health budget on mental health World Health Organization, 2011. As a result, mental health services are poorly resourced and considered inaccessible? ${ }^{9}$ Therefore, it is not a surprise that treatment rates for people with mental disorders remain low, with less than $10 \%$ receiving mental health care ${ }^{10}$.

Despite significant efforts by the Ugandan Ministry of Health to improve access to mental health services ${ }^{11}$, treatment gaps remain, in part, due to the cultural beliefs and help-seeking behaviors of the Ugandan population, who often seek traditional medicine as first-line intervention, as opposed to Westernized care ${ }^{9}$. Community-based rehabilitation, psychoeducation and social support are recommended for low resource settings such as Uganda, with assertive community care and cognitive behavioral therapy recommended as additions in higher resourced settings with stronger service-delivery platforms ${ }^{12}$.

In recent years there has been an increasing interest in exercise as a stand-alone or complementary treatment modality for people with mental illnesses such as depression $^{13}$, schizophrenia ${ }^{14}$, bipolar disorders ${ }^{15}$, alcohol use disorders ${ }^{16}$, post-traumatic stress disorder ${ }^{17}$ and anxiety disorders ${ }^{18}$. Exercise supports patients in managing their psychiatric symptoms, andit improves the physical health and quality of life ${ }^{19}$. Since exercise may be implemented at low cost and often requires no or minimal resources and can be easily tailored to accommodate co-morbidities or injuries, it may be attractive in low resource settings. The potential role of exercise interventions however seems to be given low priority and to be neglected in these low resource settings ${ }^{20}$. This is not surprising since the emphasis in health service delivery in SSA is based on the biomedical model as opposed to the biopsychosocial model with an important focus on pharmacotherapy in the management of mental disorders Mugisha, 2016.

Although physio-therapists and exercise physiologists are ideally placed to deliver exercise interventions ${ }^{21-24}$, these clinical roles are currently not available in many low resource settings in SSA countries ${ }^{20}$. In clinical practice, the existing staff including mental health nurses, occupational therapists, psychologists, doctors and psychiatrists, are currently better placed to deliver exercise counseling for people with mental illness.Qualitative ${ }^{25}$ and quantitative Stanton et al., 2015 a studies in high income countries suggest that nurses working in mental health settings acknowledge the value of exercise for people with mental illness and believe providing exercise advice is part of their role. However, such data is lacking in low resource settings, but are urgently needed in order to influence policy and practice and maximize access to the therapeutic potential of exercise at all levels of care. Such data may also help address personal factors including low confidence and limited training in exercise prescription ${ }^{26}$, and systemic barriers such as competing work priorities ${ }^{27,28}$ that limit the provision of exercise programs for people with mental illness in low resource settings.

Therefore, in order to better inform the development of exercise interventions that can be implemented in low resource settings at all levels of care in and to define specific training needs, a comprehensive assessment of the current knowledge, attitudes, beliefs and behaviors of health practitioners working in mental health settings regarding the prescription of exercise for people with a mental illness is required. The aims of the present study are twofold. Firstly, to examine the current exercise prescription practices employed by Ugandan health care professionals when working with people with mental illness. Secondly, to identify perceived barriers to exercise prescription and perceived barriers to exercise participation for people with mental illness.

\section{Methods \\ Study design}

This was a cross-sectional study.

\section{Study setting and procedure}

This study was a cross-sectional investigation undertaken at Uganda's only psychiatric hospital, the Butabika National Referral Mental Hospital. The nurses and occupation therapists working in two adult long-term care 
units were invited to participate. Combined, these two units could accommodate 110 in-patients and employs 32 nurses and 2 occupational therapists. First, all the nurses and occupational therapists were provided with an information sheet outlining the purpose of the study and with the questionnaire. The information sheet and questionnaire were provided by a research nurse who was not working in the two adult long-term care units. There were no exclusion criteria. The information sheet stated that the research nurse was available upon request to assist in the completion of the questionnaire. After one month, the research nurse gave a one-time reminder to the staff members who volunteered to participate, to complete the questionnaire within the following month. A self-administered questionnaire were used to collect data since the participants were fluent and competent in English. Content validity, conceptual equivalence and cultural sensitivity were also not an issue. No incentive for completion of the survey was offered. Participation was anonymous with questionnaires placed in a sealed box not observable to other staff members. Informed consent was assumed on completion and return of the survey. Data were collected during November and December, 2017. Ethical clearance for the study was received from the local Butabika Hospital Research Committee.

\section{Study instrument}

Participants completed the Exercise in Mental Illness Questionnaire- Health Professionals Version EMIQ-HP for which content validity and test-retest reliability have previously been established ${ }^{29}$. The instrument comprises six domains of exercise knowledge, exercise beliefs, exercise prescription behaviors, barriers to exercise, personal exercise habits and demographics. Time to complete the paper-based survey was approximately 20 minutes. Exercise-prescription practices were determined using the question; "Do you prescribe exercise to people with a mental illness?" with four response options of: "Never", "Occasionally", "Most of the time" and "Always". Self-rated knowledge and confidence to prescribe exercise for people with mental illness were assessed using Likert-response questions, 1 = "Very poor", and $5=$ "Excellent". To examine the views of other well-established treatment strategies for mental illness, respondents were asked to rate how valuable they believed each treatment was, compared to exercise, using a five-point Likert scale where 1 = "Significantly less than exercise", and 5 $=$ "Significantly better than exercise". Electroconvulsive therapy and bright light therapy were removed from the list of well-established treatments, as they are not practiced in the setting we investigated. Respondents then answered questions regarding strategies used to prescribe exercise including the frequency, intensity, duration, and type of exercise duration, frequency, using fixed response options. Level of agreement questions using a five-point Likertscale with anchors from 1 = "Strongly disagree" to5 = "Strongly agree" were used to examine respondents' views regarding barriers to exercise prescription for people with mental illness, and exercise participation by people with mental illness. Future training needs were examined with respect to level and topics of interest for professional development. Responses to statements for each subsection were then summed, thus a higher score indicates a higher level of agreement. Finally, the following demographic data were captured as part of the EMIQ-HP: gender male / female, age years, current marital status married or not married, years in profession, and full time employment yes or no.

\section{Statistical analysis}

Participant demographics, exercise prescription practices and responses to statements regarding barriers to exercise prescription for; and barriers to exercise participation by people with mental illness are reported using descriptive statistics mean $\pm \mathrm{SD}$, frequencies. In accordance with previous studies ${ }^{29,30}$, responses to statements were collapsed to three categories;"Agree", "Neutral", and "Disagree". Since the Likert scale responses are not assumed to be on an equal interval scale, and frequency of responses to "Strongly agree" and "Agree" are low, these responses were collapsed to "Agree". Based on rating scale optimization, collapsing the positive responses "Strongly agree" and "Agree" into one category is logical and does not create an artificial new category. Similarly, combining negative responses "Strongly disagree" and "Disagree" demonstrates the strength of these responses, compared to neutral and positive responses ${ }^{31}$.

\section{Results \\ Participants}

Thirty-one health care professionals, representing 91\% of potential respondents completed the EMIQ-HP. Respondents included 10 nurses, 19 nurses with specialist mental health nursing qualification and 2 occupational therapists. The characteristics of respondents are shown in Table 1. 
Table 1. Demographic characteristics of respondents $n=31$

\begin{tabular}{lcc}
\hline Characteristic & Mean \pm SD & Range \\
\hline Age years & $31.2 \pm 7.1$ & $22-48$ \\
Years in profession & $7.3 \pm 7.1$ & $<1-34$ \\
\hline & Number of respondents & Proportion of respondents \\
\hline Gender male & 20 & $64 \%$ \\
Marital status married & 21 & $68 \%$ \\
Full time employment yes & 27 & $88 \%$ \\
\hline
\end{tabular}

\section{Frequency of exercise prescription}

Three respondents 10\% reported 'Always' prescribing exercise, $3(10 \%)$ reported prescribing exercise 'Most of the time', $23(74 \%)$ reported prescribing exercise 'Occasionally' and two 6\% reported 'Never' prescribing exercise.

Knowledge about and confidence regarding exercise prescription

Sixteen respondents $(52 \%)$ indicated that they had a formal training in exercise prescription. The mean $\pm S D$ response for self-reported knowledge and confidence scores was3.6 \pm 0.6 and 3.6 \pm 0.5 , respectively. Nine respondents 29\% reported a "Good" or "Excellent" knowledge of exercise prescription for mental illness. Similarly, 10 respondents $(32 \%)$ reported that they are confident at prescribing exercise for people with mental illness to be "Good" or "Excellent".

Views of health care professionals comparing established treatments to exercise for the treatment of mental illness

Overall, between $74 \%$ and $90 \%$ of respondents believed other treatment modalities to be of equal or greater value compared to exercise. The majority of respondents $\mathrm{n}=24,77 \%$ believed medication is 'Somewhat', or 'Significantly' more valuable than exercise. Between $45 \%$ and $65 \%$ of respondents believed other treatment modalities are 'Somewhat', or 'Significantly' more valuable than exercise. Slightly more than one-third $n=11,35 \%$ of respondents believed social skills training is of equal value to exercise. A summary of the findings regarding the value to treatments compared to exercise is shown in Table 2. 
Table 2. Comparison of established treatments to exercise for the treatment of mental illness.

\begin{tabular}{lccccc}
\hline & $\begin{array}{c}\text { Significantly } \\
\text { less than } \\
\text { exercise }\end{array}$ & $\begin{array}{c}\text { Somewhat } \\
\text { less than } \\
\text { exercise }\end{array}$ & $\begin{array}{c}\text { Of equal } \\
\text { value to } \\
\text { exercise }\end{array}$ & $\begin{array}{c}\text { Somewhat } \\
\text { better than } \\
\text { exercise }\end{array}$ & $\begin{array}{c}\text { Significantly } \\
\text { better than } \\
\text { exercise }\end{array}$ \\
\hline $\begin{array}{l}\text { Medication [n,\%] } \\
\begin{array}{l}\text { Social support } \\
{[\mathrm{n}, \%]}\end{array}\end{array}$ & $13 \%$ & $413 \%$ & $26 \%$ & $826 \%$ & $1652 \%$ \\
$\begin{array}{l}\text { Family therapy } \\
{[\mathrm{n}, \%]}\end{array}$ & $00 \%$ & $722 \%$ & $929 \%$ & $1135 \%$ & $310 \%$ \\
$\begin{array}{l}\text { Social skill } \\
\text { training [n,\%] }\end{array}$ & $00 \%$ & $310 \%$ & $1135 \%$ & $1342 \%$ & $413 \%$ \\
$\begin{array}{l}\text { Cognitive } \\
\text { behavioural } \\
\text { therapy [n,\%] }\end{array}$ & $00 \%$ & $619 \%$ & $517 \%$ & $1548 \%$ & $517 \%$ \\
$\begin{array}{l}\text { Vocational } \\
\text { rehabilitation } \\
\text { [n,\%] }\end{array}$ & $00 \%$ & $310 \%$ & $826 \%$ & $826 \%$ & $1238 \%$ \\
\hline
\end{tabular}

\section{Exercise prescription strategies}

When considering the strategies used to prescribe exercise to people with mental illness, personal discussion, including the development of an individualized program was the most frequently used strategy $n=19 / 29,65 \%$. Only one respondent indicated referral to an exercise physiologist / physiotherapist for exercise prescription. The most commonly reported recommendation for exercise frequency was to exercise "As often as they can" $\mathrm{n}=12 / 29,41 \%$ followed by on "Most days of the week" $\mathrm{n}=10 / 29,34 \%$. The most frequently recommended exercise intensity for people with mental illness was "At a level that makes them feel good" $n=9 / 29,31 \%$, followed by "Moderate" $n=7 / 29,24 \%$. "30 minutes per day" $\mathrm{n}=11 / 29,38 \%$ was the most frequently prescribed exercise duration followed by "Exercising as long as they can" $\mathrm{n}=7 / 29,24 \%$. Relaxation exercises such as yoga or Tai Chi $n=16 / 29,55 \%$ were the most commonly prescribed mode of exercise followed by aerobic exercise $n=10 / 29$, $34 \%$.

\section{Barriers to exercise prescription}

Responses to statements regarding the barriers to exercise prescription for people with mental illness are shown in Table 3. When collapsed to categories of 'Agree', 'Neutral', and 'Disagree',just over half $n=18,58 \%$ agreed that patient's mental health makes it impossible for them to participate in exercise. Almost half $n=13,45 \%$ agreed that getting injured during exercise is a concern. Overwhelmingly however, $87 \%$ of respondents $n=27$ agreed that exercise will be beneficial, and were interested in exercise prescription for this population. Only $13 \% n=4$ agreed that exercise prescription is not part of their job, but $16 \%$ agreed that they did not know how to prescribe exercise for people with mental illness. Importantly, 71\% $n=22$ agreed that exercise prescription for people with mental illness is best delivered by an exercise professional. 
Table 3. Level of agreement $[n \%]$ with statements regarding barriers to exercise prescription for people with mental illness

\begin{tabular}{|c|c|c|c|c|c|}
\hline & $\begin{array}{l}\text { Strongly } \\
\text { disagree }\end{array}$ & Disagree & $\begin{array}{c}\text { Neither } \\
\text { disagree / } \\
\text { agree }\end{array}$ & Agree & $\begin{array}{c}\text { Strongly } \\
\text { agree }\end{array}$ \\
\hline $\begin{array}{l}\text { Their mental health makes } \\
\text { it impossible for them to } \\
\text { participate in exercise }\end{array}$ & $5,17 \%$ & $4,13 \%$ & $4,13 \%$ & $10,32 \%$ & $8,26 \%$ \\
\hline $\begin{array}{l}\text { I'm concerned exercise } \\
\text { might make their } \\
\text { condition worse }\end{array}$ & $3,10 \%$ & $15,48 \%$ & $4,13 \%$ & $8,26 \%$ & $1,3 \%$ \\
\hline $\begin{array}{l}\text { I am not interested in } \\
\text { prescribing exercise for } \\
\text { people with a mental } \\
\text { illness }\end{array}$ & $6,19 \%$ & $21,68 \%$ & $1,3 \%$ & $1,3 \%$ & $2,6 \%$ \\
\hline $\begin{array}{l}\text { I don't believe exercise } \\
\text { will help people with a } \\
\text { mental illness }\end{array}$ & $7,23 \%$ & $20,64 \%$ & $2,6 \%$ & $1,3 \%$ & $1,3 \%$ \\
\hline $\begin{array}{l}\text { Their physical health } \\
\text { makes it impossible for } \\
\text { them to participate in } \\
\text { exercise }\end{array}$ & $4,13 \%$ & $17,55 \%$ & $3,10 \%$ & $3,10 \%$ & $4,13 \%$ \\
\hline $\begin{array}{l}\text { I'm concerned they might } \\
\text { get injured while } \\
\text { exercising }\end{array}$ & $4,13 \%$ & $7,23 \%$ & $7,23 \%$ & $11,35 \%$ & $2,6 \%$ \\
\hline $\begin{array}{l}\text { People with a mental } \\
\text { illness won't adhere to an } \\
\text { exercise program }\end{array}$ & $3,10 \%$ & $10,32 \%$ & $7,23 \%$ & $7,23 \%$ & $4,13 \%$ \\
\hline $\begin{array}{l}\text { My workload is already } \\
\text { too excessive to include } \\
\text { prescribing exercise to } \\
\text { people with a mental } \\
\text { illness. }\end{array}$ & $7,23 \%$ & $17,55 \%$ & $1,3 \%$ & $5,17 \%$ & $1,3 \%$ \\
\hline $\begin{array}{l}\text { Prescribing exercise to } \\
\text { people with a mental } \\
\text { illness is not part of my } \\
\text { job }\end{array}$ & $5,17 \%$ & $19,60 \%$ & $3,10 \%$ & $0,0 \%$ & $4,13 \%$ \\
\hline $\begin{array}{l}\text { I do not know how to } \\
\text { prescribe exercise to } \\
\text { people with a mental } \\
\text { illness }\end{array}$ & $2,6 \%$ & $19,60 \%$ & $5,17 \%$ & $4,13 \%$ & $1,3 \%$ \\
\hline $\begin{array}{l}\text { Prescription of exercise to } \\
\text { people with mental illness } \\
\text { is best delivered by an } \\
\text { exercise professional. }\end{array}$ & $3,10 \%$ & $3,10 \%$ & $3,10 \%$ & $14,45 \%$ & $8,26 \%$ \\
\hline
\end{tabular}

\section{Barriers to participation}

The agreement with statements expressed by people with mental illness regarding exercise participation is shown in Table 4. In a manner similar to the responses to statements regarding barriers to exercise prescription, scale optimization was performed to result in three categories.
When collapsed to categories of "Agree", "Neutral", and "Disagree", almost three-quarters of respondents $n=23$, $74 \%$ agreed with the consumer view that "There is too much stigma attached to having a mental illness." while more than half $\mathrm{n}=18,58 \%$ agreed with the statement "There are too many side effects from the medications." 


\section{Training needs for health care professionals}

Participants were cognizant of the need for ongoing professional development in the field. More than two-thirds of respondents 23/31 indicated they would "Definitely" attend further training for exercise prescription for people with mental illness, with the most commonly reported topics of interest being "How to assess the patients' suitability for physical activity?" $n=22,71 \%$ and "How to get and maintain motivation in people with mental illness?" $\mathrm{n}=18,58 \%$.

\section{Discussion}

\section{General findings}

The present study is the first to provide new insight from the perspectives of health professionals working in a long-term adult inpatient mental health facility in a low resource country, with regard to the prescription of exercise to people with mental illness. The 31 respondents in the present survey represent approximately $90 \%$ of the health care professionals working in the mental health setting explored.

The vast majority 29/31, 94\% reported that they prescribed at least "occasionally" exercise to their patients. The positive attitude of nurses and occupational therapists towards exercise is in line with previous research in other parts of the world. For example, a British study ${ }^{32}$ reported that $77 \%$ of mental health nurses felt that providing exercise advice and referring to a community facility was part of their role while in an Australian study Stanton et al. ${ }^{33}, 2015 \mathrm{~b} 72 \%$ of the nurses reported prescribing exercise to mental health consumers.

Participants self-reported a high level of knowledge and confidence in prescribing exercise for people with mental illness. This high level of knowledge is also reflected in the exercise-prescription parameters for exercise frequency, intensity, duration, and type recommended by respondents. These are consistent with those recommended for people with mental illness ${ }^{33,34}$. International guidelines call for aerobic exercise to be performed 3 to 5 days per week for $30 \mathrm{~min}$ at low-to-moderate or self-selected intensity $^{33,34}$. The popular view regarding exercising at a level that makes them feel good, and for as long as they like, is consistent with the use of autonomous regulation in exercise prescription for people with mental illness ${ }^{35-37}$ and consistent with approaches used in other health professional groups ${ }^{38,39}$.
The high level of knowledge and confidence in prescribing exercise for people with mental illness is perhaps unsurprising given that more than half of the existing work staff indicated that they are trained in exercise prescription and implementing lifestyle interventions for people with chronic or complex health conditions, a rate which is for example much higher than in Australia where only $11 \%$ of the nurses reported having any formal training in exercise prescription ${ }^{38}$. Since Butabika Hospital is a national referral hospital, many of its staff are likely also more exposed to information related to exercise compared to work staff in more rural areas, owing to the fact that the hospital runs a bigger budget, from both local resources and donors for continued medical education ${ }^{27}$, ${ }^{28}$. On the other hand, almost $75 \%$ of the respondents indicated that they would "definitely" attend further training for exercise prescription for people with mentalillness, in particular related to how to assess patients and how to motivate them towards an active lifestyle. More than seventy percent of the participants also reported that exercise to people with mental illness is actually best delivered by an exercise professional, although only one respondent referred patients to such an exercise professional. A potential reason for the very low referral rate is the lack of exercise specialists working in mental health care settings in low income countries ${ }^{20}$. It is likely that due to the strong biomedical focus on pharmacotherapy ${ }^{27}$, policy makers are yet to be fully aware of the benefits of including exercise specialists in the Ugandan mental health care system. Hence, a need to re-orient the current health care system including policy makers to embrace these professions in the management of mental health problems is needed. Internationally, exercise physiologists 24 and physiotherapists 21 are the health professional groups with expertise in exercise prescription for people with mentalillness. Both health professional groups are trained in exercise prescription for people with chronic and complex health conditions including for those with mental illness. Thus, exercise professionals are able to develop and deliver cost- and resource-efficient exercise interventions. To date, however, few people in Uganda, and Sub-Saharan African as a whole with mental illness are referred to exercise specialists in primary health care settings $\mathrm{s}^{27,28}$. One of reasons might be the lack of mental health training for these exercise professionals in this part of the world ${ }^{20}$.

Despite the fact that the respondents reported a high lev- 
el of knowledge and confidence in prescribing exercise for people with mental illness, the potential of exercise within the multidisciplinary treatment seems not yet to be fully endorsed in low resource countries. "Standard treatments" for mental illness were generally perceived as of greater therapeutic value to exercise. One reason might be the previously reported strong biomedical focus, while clinicians tend to favor interventions related to their own discipline, for example occupational therapists favor vocational rehabilitation and social skills training while nurses favor family support. Another issue might be the socio-cultural views of mental illness whereby potential patients do not routinely seek treatment due to the high levels of stigma, and where treatment is provided traditionally through non-Westernized approaches. Thus, exercise as part of any treatment strategy is largely underutilized.

In the current study, we also explored barriers to exercise prescription for health care professionals and participation by mental health consumers. A previous study in physical therapists demonstrated that a-motivation by mental health consumers is the most significant barrier to exercise participation ${ }^{40}$, while barriers to exercise prescription by nurses working in mental health in Australia extend to the systemic level ${ }^{41}$. For example, previous research highlighted how the fragmentation of roles, prioritization of other tasks, lack of time, and limited resources impact on the prescription of exercise by nurses working in mental health in Australia ${ }^{41}$. Surprisingly, in our study these barriers were not endorsed by more than half of our respondents. In our study, respondents agreed with a number of statements regarding barriers to exercise participation proposed by people with mental illness. This was especially the case for statements located more at the individual level such as the side effects from pharmacotherapy, and at the community level where stigma and negative attitudes surrounding mental illness were considered a major barrier for people with mental illness to engage in exercise. Therefore, in order to facilitate exercise uptake, deliberate efforts need to be undertaken within the hospital to assist patients in coping with the side effects of their pharmacotherapy while at the community level public health campaigns are needed to reduce the stigma associated with mental illness. These changes should be augmented by professional development opportunities suggested by respondents including the assessment, initiation, and motivation for continued exercise participation by people with mental illness.

\section{Limitations}

The present study should be considered in the light of some limitations. First, we were not able to obtain completed surveys from all health care professionals working in mental health setting where the study was undertaken. This could be due to the time commitment required, personal concerns regarding the knowledge related to exercise for people with mental illness and the lack of incentive for participation. Uganda also has a small mental health workforce with around 28 psychiatrists and 230 mental health nurses, most of whom work at Butabika ${ }^{42}$, thus competing priorities may have affected the survey response rate. However, considerable effort was directed towards recruitment and the proportion of professionals who completed surveys represents approximately 90\% of the eligible staff. Second, the present survey was also limited to only one hospital. Butabika is however the only national mental health referral center in Uganda. Together with a small cohort, the generalizability of our findings remains to be confirmed while interdisciplinary comparisons were not possible. Third, although the EMIQ-HP has been validated before in Australia ${ }^{29}$, the validity for the mental health workforce in low income countries is unknown.

\section{Conclusion}

The present findings suggest nurses and occupational therapists who participated in this study are supportive of exercise, and those who prescribe exercise do so in accordance with accepted protocols. Moreover, respondents disagree with many of the commonly cited barriers to exercise prescription and participation in the current literature. Regarding barriers to exercise participation, reducing stigma at community level should be prioritized. Collaboration with exercise professionals such as exercise physiologists and physiotherapists as part of a multidisciplinary approach to mental health care could increase exercise uptake and consequently improve health outcomes for mental health consumers. Further examination in larger cohorts including all relevant healthcare disciplines will progress our understanding of the delivery of exercise for people with mental illness in low resourced settings. 


\section{Acknowledgements}

The authors would like to thank the nurses of the Butabika National Referral and Mental Health Hospital who completed the questionnaires for the purpose of this study.

\section{Conflict of interest}

None to declare from either author.

\section{Funding}

This research was funded by Geestkracht VZW.

\section{Role of funding source}

The funding organization had no role in the research at any stage, nor influenced the decision to publish the article.

\section{References}

1. Whiteford HA, Degenhardt L, Rehm J, Baxter AJ, Ferrari AJ, Erskine HE, et al. Global burden of disease attributable to mental and substance use disorders: findings from the Global Burden of Disease Study 2010. The Lancet. 2013;3829904:1575-86. doi: 10.1016/S014067361361611-6.

2. Bloom DE, Cafiero E, Jané-Llopis E, Abrahams-Gessel S, Bloom LR, Fathima S, et al. The global economic burden of noncommunicable diseases. Program on the Global Demography of Aging, 2012.

3. Vancampfort D, Stubbs B, Mitchell AJ, De Hert M, Wampers M, Ward PB, et al. Risk of metabolic syndrome and its components in people with schizophrenia and related psychotic disorders, bipolar disorder and major depressive disorder: a systematic review and meta-analysis. World Psychiatry. 2015;143:339-47. doi: 10.1002/ wps.20252.

4. Vancampfort D, Correll CU, Galling B, Probst M, De Hert M, Ward PB, et al. Diabetes mellitus in people with schizophrenia, bipolar disorder and major depressive disorder: a systematic review and large scale meta-analysis. World Psychiatry. 2016; 152:166-74. doi: 10.1002/ wps.20309.

5. Stubbs B, Mitchell AJ, De Hert M, Correll CU, Soundy A, Stroobants M, et al. The prevalence and moderators of clinical pain in people with schizophrenia: A systematic review and large scale meta-analysis. Schizophrenia Research. 2014;1601:1-8. doi: 10.1016/j.schres.2014.10.017.

6. Stubbs B, Eggermont L, Mitchell AJ, De Hert M, Cor- rell CU, Soundy A, et al. The prevalence of pain in bipolar disorder: a systematic review and large-scale meta-analysis. Acta Psychiatrica Scandinavica. 2015;1312:75-88. doi: 10.1111/acps.12325.

7. De Beaudrap P, Mac-Seing M, Pasquier E. Disability and HIV: a systematic review and a meta-analysis of the risk of HIV infection among adults with disabilities in Sub-Saharan Africa. AIDS Care. 2014;2612:1467-76. doi: 10.1080/09540121.2014.936820

8. Kinyanda E, Hoskins S, Nakku J, Nawaz S, Patel V. Prevalence and risk factors of major depressive disorder in HIV/AIDS as seen in semi-urban Entebbe district, Uganda. BMC Psychiatry. 2011;111:1. doi: 10.1186/1471244X-11-205.

9. Nsereko JR, Kizza D, Kigozi F, Ssebunnya J, Ndyanabangi S, Flisher AJ, et al. Stakeholder's perceptions of help-seeking behaviour among people with mental health problems in Uganda. International Journal of Mental Health Systems. 2011;51:5. doi: 10.1186/1752-4458-5-5.

10. Lund C, Alem A, Schneider M, Hanlon C, Ahrens $\mathrm{J}$, Bandawe $\mathrm{C}$, et al. Generating evidence to narrow the treatment gap for mental disorders in sub-Saharan Africa: rationale, overview and methods of AFFIRM. Epidemiology and Psychiatric Sciences. 2015;2403:233-40. doi: $10.1017 /$ S204579601500028111.

11. Ndyanabangi S, Basangwa D, Lutakome J, Mubiru C. Uganda mental health country profile. International Review of Psychiatry. 2004;161-2:54-62. doi: 10.1080/09540260310001635104

12. de Jesus Mari J, Razzouk D, Thara R, Eaton J, Thornicroft G. Packages of care for schizophrenia in low-and middle-income countries. PLoS Medicine. 2009;610:e1000165. doi: 10.1371/journal.pmed.1000165. 13. Schuch FB, Vancampfort D, Richards J, Rosenbaum S, Ward PB, Stubbs B. Exercise as a treatment for depression: a meta-analysis adjusting for publication bias. Journal of Psychiatric Research. 2016;77:42-51. doi: 10.1590/15164446-2016-1915.

14. Firth J, Cotter J, Elliott R, French P, Yung A. A systematic review and meta-analysis of exercise interventions in schizophrenia patients. Psychological Medicine. 2015;457:1343-61. doi: 10.1017/S0033291714003110.

15. Melo MCA, Daher EDF, Albuquerque SGC, de Bruin VMS. Exercise in bipolar patients: A systematic review. Journal of Affective Disorders. 2016;198:32-8. doi:10.1016/j. jad.2016.03.004.

16. Hallgren M, Vancampfort D, Giesen ES, Lundin A, 
Stubbs B. Exercise as treatment for alcohol use disorders: systematic review and meta-analysis. British Journal of Sports Medicine. 2017: 5114:1058-1064. doi: 10.1136/ bjsports-2016-096814.

17. Rosenbaum S, Vancampfort D, Steel Z, Newby J, Ward PB, Stubbs B. Physical activity in the treatment of post-traumatic stress disorder: A systematic review and meta-analysis. Psychiatry Research. 2015;2302:130-6. doi: 10.1016/j.psychres.2015.10.017.

18. Stubbs B, Koyanagi A, Hallgren M, Firth J, Richards J, Schuch F, et al. Physical activity and anxiety: A perspective from the World Health Survey. Journal of Affective Disorders. 2017;208:545-52. doi: 10.1016/j.jad.2016.10.028.

19. Rosenbaum S, Tiedemann A, Sherrington C, Curtis J, Ward PB. Physical activity interventions for people with mental illness: a systematic review and meta-analysis. Journal of Clinical Psychiatry. 2014;759:964-74. doi: 10.4088/ JCP.13r08765.

20. Vancampfort D, Stubbs B, De Hert M, du Plessis C, Gbiri CAO, Kibet J, et al. A systematic review of physical activity policy recommendations and interventions for people with mental health problems in Sub-Saharan African countries. Pan African Medical Journal. 2017;26104. doi: 10.11604/pamj.2017.26.104.10051.

21. Stubbs B, Probst M, Soundy A, Parker A, De Herdt A, De Hert M, et al. Physiotherapists can help implement physical activity programmes in clinical practice. The British Journal of Psychiatry. 2014; 2042:164. doi: 10.1192/ bjp.204.2.164.

22. Vancampfort D, Rosenbaum S, Schuch FB, Ward PB, Probst M, Stubbs B. Prevalence and predictors of treatment dropout from physical activity interventions in schizophrenia: a meta-analysis. General Hospital Psychiatry. 2016;39:15-23. doi:10.1016/j.genhosppsych.2015.11.008. 23. Stubbs B, Vancampfort D, Rosenbaum S, Ward PB, Richards J, Soundy A, et al. Dropout from exercise randomized controlled trials among people with depression: A meta-analysis and meta regression. Journal of Affective Disorders. 2016;190:457-66. doi: 10.1016/j. jad.2015.10.019.

24. Lederman O, Grainger K, Stanton R, Douglas A, Gould K, Perram A, et al. Consensus statement on the role of Accredited Exercise Physiologists within the treatment of mental disorders: a guide for mental health professionals. Australasian Psychiatry. 2016; 244:347-51. doi: $10.1177 / 1039856216632400$.
25. Robson D, Haddad M, Gray R, Gournay K. Mental health nursing and physical health care: A cross-sectional study of nurses' attitudes, practice, and perceived training needs for the physical health care of people with severe mental illness. International Journal of Mental Health Nursing. 2013;225:409-17. doi: 10.1111/j.1447-0349.2012.00883.x. 26. Verhaeghe N, De Maeseneer J, Maes L, Van Heeringen C, Annemans L. Perceptions of mental health nurses and patients about health promotion in mental health care: a literature review. Journal of Psychiatric and Mental Health Nursing. 2011;186:487-92. doi: 10.1111/j.13652850.2011.01692.x.

27. Mugisha J, Ssebunnya J, Kigozi FN. Towards understanding governance issues in integration of mental health into primary health care in Uganda. International Journal of Mental Health Systems. 2016;101:1. doi: 10.1186/ s13033-016-0057-7.

28. Mugisha J, Abdulmalik J, Hanlon C, Petersen I, Lund C, Upadhaya $\mathrm{N}$, et al. Health systems context s for integrating mental health into primary health care in six Emerald countries: a situation analysis. International Journal of Mental Health Systems. 2017;111:7. doi: 10.1186/s13033016-0114-2.

29. Stanton R, Happell B, Reaburn P. The development of a questionnaire to investigate the views of health professionals regarding exercise for the treatment of mental illness. Mental Health and Physical Activity. 2014;73:177-82. doi: 10.1016/j.mhpa.2014.06.001.

30. Stanton R, Reaburn P, Happell B. Barriers to exercise prescription and participation in people with mental illness: the perspectives of nurses working in mental health. Journal of Psychiatric and Mental Health Nursing. 2015;226:440-8. doi: 10.1111/jpm.12205.

31. Royal KD, Ellis A, Ensslen A, Homan A. Rating scale optimization in survey research: An application of the Rasch rating scale model. Journal of Applied Quantitative Methods. 2010;54.

32. Howard L, Gamble C. Supporting mental health nurses to address the physical health needs of people with serious mental illness in acute inpatient care settings. Journal of Psychiatric and Mental Health Nursing. 2011;182:105-12. doi: 10.1111/j.1365-2850.2010.01642.x.

33. Stanton R, Reaburn P. Exercise and the treatment of depression: a review of the exercise program variables. Journal of Science and Medicine in Sport. 2014;172:177-82. doi: 10.1016/j.jsams.2013.03.010. 
34. Vancampfort D, Hert MD, Skjerven LH, Gyllensten AL, Parker A, Mulders N, et al. International Organization of Physical Therapy in Mental Health consensus on physical activity within multidisciplinary rehabilitation programmes for minimising cardio-metabolic risk in patients with schizophrenia. Disability and Rehabilitation. 2012;341:1-12. doi: 10.3109/09638288.2011.587090.

35. Vancampfort D, De Hert M, Vansteenkiste M, De Herdt A, Scheewe TW, Soundy A, et al. The importance of self-determined motivation towards physical activity in patients with schizophrenia. Psychiatry Research. 2013; 2103:812-8. doi: 10.1016/j.psychres.2013.10.004.

36. Vancampfort D, Stubbs B, Venigalla SK, Probst M. Adopting and maintaining physical activity behaviours in people with severe mental illness: The importance of autonomous motivation. Preventive Medicine. 2015. 81:21620. doi: 10.1016/j.ypmed.2015.09.006.

37. Vancampfort D, De Hert M, Broderick J, Lederman $\mathrm{O}$, Firth J, Rosenbaum S, et al. Is autonomous motivation the key to maintaining an active lifestyle in first-episode psychosis? Early Intervention in Psychiatry. 2016. doi: 10.1111/eip.12373.
38. Stanton R, Happell B, Reaburn P. Investigating the exercise-prescription practices of nurses working in inpatient mental health settings. International Journal of Mental Health Nursing. 2015;242:112-20. doi: 10.1111/inm.12125. 39. Stanton R, Rosenbaum S, Lederman O, Happell B. Implementation in action: how Australian Exercise Physiologists approach exercise prescription for people with mental illness. Journal of Mental Health. 2017:1-7. doi: 10.1080/09638237.2017.1340627.

40. Soundy A, Stubbs B, Probst M, Hemmings L, Vancampfort D. Barriers to and facilitators of physical activity among persons with schizophrenia: A survey of physical therapists. Psychiatric Services. 2014;655:693-6. doi:10.1176/appi.ps.201300276

41. Happell B, Scott D, Platania-Phung C, Nankivell J. Nurses' views on physical activity for people with serious mental illness. Mental Health and Physical Activity. 2012;51:412. doi: 10.1016/j.mhpa.2012.02.005.

42. Murray JS, Ainslie L, Alpough M, Schramm C, Showalter $\mathrm{C}$. The scope of mental illness and status of psychiatric care in Uganda. Issues in Mental Health Nursing. 2015;3611:877-83. doi: 10.3109/01612840.2015.1049311. 